\title{
A Brief Analysis of the Phenomenon of "Keyboard Chivalry" among Young College Students
}

\author{
Rongrong Wang \\ Tianjin University of Commerce, Tianjin 300134
}

\begin{abstract}
The emergence of the "Keyboard man" group is the result of the comprehensive effects of many factors. The ideological and political education of the "Keyboard man" group should follow the principles of equality, tolerance, and participation, and use the core socialist values to guide them to observe the value goals and standardize speech behavior.
\end{abstract}

Keywords: Keyboard Man; Cause; Influence

"Keyboard man", a new Internet term, is no longer unfamiliar, and has even entered our lives. As the Internet becomes a part of our lives, more and more keyboard heroes appear, especially in the network era of the "original", and have entered the society of young college students. And as the "keyboard man" in the main force.

\section{Historical background}

College students are generally between 18 and 22 years old. Living in the era of Internet and computer popularization, their toys from childhood are no longer rubber bands, skipping rope or mud, but computers, tablets and mobile phones.

The network is a very large world, in the professional serious it is the data, is the code, is the machine. For the older generation, it's something new, it's a tool. But for the natives, he was a part of life, an indispensable part. It is rich and colorful, it has our life inside, also has the life of others, that is a spiritual world. It is as much a part of life as our real life.

\section{Convenient web tools}

The network world itself is rich and colorful, it renders the spiritual world of everyone. It allows people to learn a lot, see a lot of the outside world, and in recent years it's been turning on "new features," for better or worse. For example, it has become an important tool for public opinion. Many things, whether true or false, whether right or wrong, whether personal privacy or not, will be posted on the Internet as long as there is a "flash point".

The university life is less binding without parents, the study is relaxed enough time, the pressure is reduced sharply, the spiritual world is empty. At this time, the Internet is the biggest part of many people's lives. The word "indoorsy" came into being, and as a result, the "keyboard warrior" among teenage college students has come into being.

\section{Social phenomenon and human heart}

With the development of the network era, more and more beautiful and dark, show in people's eyes. It's rare to actually stand up and do something, solve something, or help. And the network era is to give free play to the public opinion platform.

At the beginning of man, nature is good. There is justice and fairness in everyone's heart. But not everyone has the guts to really speak up or act directly. Therefore, more people choose to be an honest and fair knight in the online world, because they can ensure their safety in real life and express their inner feelings at the same time. Don't worry about reality.

The downside of the online world is that what we see is not necessarily true. Because what we see is described by other people in words or pictures, we don't know the cause and effect of specific things, and what is even described may not be true, but the power of language is powerful. If it touches someone's psychological defense or principles, then it will arouse everyone's emotions.

As a fresh force of "chivalrous men", young college students are at a young age when they have just come into contact with the society and their values, world outlook and views of right and wrong are preliminarily formed. They worship heroes and hate evil. After receiving so many years of education, I have a solid foundation in literature, but in fact, it is still relatively simple for society, more things, look more superficial, more easily affected by the appearance.

A child may see more of the dark side of contact, dark and distorted in the heart, the real world has all kinds of laws and other restrictions, things that cannot be achieved, more people can be displayed on the Internet. At this time, the truth itself is no longer 
important to them. What is important is that they are satisfied with themselves and their spiritual world is comfortable, so they will feel more comfortable in real life.

\section{The impact of the appearance of "Keyboard Man"}

The impact of the "keyboard man" has been mixed.

In the past, when there were difficulties, people used to think of people around them, relatives, friends and neighbors. But now, in addition to these people, more people choose the network this big world, put the difficulties on the network, the real situation is also announced in front of everyone, capable, saw, will help, and this time, "keyboard man" played a role. First, they can use their own Internet resources to increase the scope of publicity for these things in need of help. Second, their rich vocabulary, their justice, their enthusiasm can let more people have a deeper understanding of the matter, through their voice, inspire more people, give love, to help the people who really need help.

In recent years, more and more "Shuidi" appeared in people's sight, "Shuidi" mostly help the poor, seriously ill, but have no money to treat. A college student's father is ill, the family financial difficulties, there is no money for his father to see a doctor. His classmates recommended "Water drop chip" to him, and sent this message in the class group, the whole class helped him, published the circle of friends, published the forum. The keyboarders add their own language to describe the actual difficulties in a profound way.

However, the appearance of "keyboard man" does bring a lot of negative effects, resulting in the current society for the "keyboard man", the term is divided between praise and criticism. Also, because "keyboard warrior" has a fermenting effect, it can make a thing spread quickly and help people. Similarly, there are plenty of examples of how a small thing can turn into something big.

There has been such a case, there is a case, a man in changed railway station because of infarction faint, happened to have two girls by, the two girls are medical university students. It is well known that medical students take an oath when they enter school. Healing the wounded and rescuing the dying is their aim. Two kind children, when they saw the people around them fainted, their first reaction was to help them. However, after some treatment, it was a pity that the man still died. Many of the people who saw it, took pictures and posted them on the Internet. Some "keyboard heroes" begin to have rich imagination, divergent thinking, whim.

"How can a student, who has no medical certificate, directly save lives?"

"Maybe you could have waited for the paramedics to come and been killed by two girls."

"I don't know whether it's to save or harm."

"A fling"

"College students are mostly just armchair warriors"

There are many such remarks, and some people write the plot in them.

"The next day the man's family took two college students to court because the two girls didn't have medical certificates. How about this scenario?"

There are a lot of people who don't know the beginning and end of things, affected by such "keyboard man". The same two rescue girls, originally left, see the man did not save back, very sad, with tears left. As a result, my good deeds have been misunderstood and even abused by some people.

Fortunately, there are some people, who are rational, who also act as keyboard heroes in this case.

"The two girls haven't graduated yet, but they've gone a long way to save lives."

"What's valuable is the bravery of the two girls, and whether they succeed or not, there are fewer people who can actually stand up and do something about it now."

Due to the lack of social experience, some young college students are already very angry or moved when they see many things. They are greatly affected by emotions and cannot seriously analyze the true thoughts of the facts. Therefore, when they talk online, they often just judge the right and wrong of the things they see. Sometimes it can really help some people, but sometimes it can really hurt some people.

\section{Correct guidance}

Young college students have basic knowledge and values, but they need more guidance when they first enter the society. With the development of society and the progress of The Times, these "indigenous people" of the Internet will not be far away from the "online". Then what the society needs to provide them is the right guidance.

In childhood education, the truth of life, the ability to distinguish between right and wrong, need to work together from family education to school education. Especially for modern college students, they should be self-disciplined and learn to control their own time.

In the judgment, reprimanding young college students ignorant, can only do a hypocritical "keyboard man", little do not know, he has been a member of the keyboard man. As a matter of fact, college students have potential and enthusiasm. If they can guide the new force correctly, they will bring positive energy with them. In this Internet era, all the positive energy and warmth are surging out.

In addition, college students should properly arrange their time. Although the intense college entrance examination life has come to an end and the current academic work is no longer onerous, it is left for everyone to enrich themselves and improve themselves in other aspects. Some people can use this time to study their hobbies or even become a career, learn some skills outside the books, learn more about the society, get involved in it, and master more survival skills and development paths.

Likewise, we should cultivate children's courage and perseverance. If only in the virtual world dare to be a righteous knight, but in the real world is cowardly and timid, then the society in the online world looks healthy, but in fact it is very sick. Therefore, 
as the backbone of these societies and future masters of the society, young college students need more attention and guidance from the society. I hope this society brings them warmth, and in the future they will give back to the society.

So that the keyboard man can actually stand up in the online world, but also stand up in the real world. Let the sun shine on more parts of the world, the young college students "keyboard man" team, can be in a great way.

\section{References}

1 Shen Zhuanghai, Dong Xiangbin. On the improvement of the quality of ideological and political work in colleges and universities in the new era[J]. Ideological and Theoretical Education, 2018(8): 11-15, 101.

2 Cheng Shibo. On the characteristics and guiding countermeasures of Internet public opinion in the era of "post truth"[J]. Ideological and Theoretical Education, 2018(9): 77-81.

3 Bi Shicheng. We cannot rely on "Keyboard Man” to inspire courage to do what is right [N]. People's Daily, 2014-06-04 (005).

4 Zhang Cancan. "Keyboard Man”, are you really worthless[J]. Youth Reporter, 2016(31):95. 